\title{
1 Continuous activity and no cycling of clock genes in the Antarctic midge
}

2 during the polar summer

4 Alena Kobelkova $^{\text {a,\# }}$, Shin G. Goto ${ }^{\text {b,\# }, \text { Justin T. Peyton }}{ }^{a}$, Tomoko Ikeno ${ }^{\text {, }}$, Richard E. Lee,

$5 \quad$ Jr. $^{\text {c }}$ and David L. Denlinger ${ }^{\mathrm{a}, *}$

6

$7 \quad{ }^{a}$ Departments of Entomology and Evolution, Ecology and Organismal Biology, Ohio State

8 University, Columbus, $\mathrm{OH} 43210$, USA

$9 \quad{ }^{\mathrm{b}}$ Graduate School of Science, Osaka City University, Osaka 558-8585, Japan

10

${ }^{\mathrm{c}}$ Department of Zoology, Miami University, Oxford, OH 45056, USA

$11 \quad$ Equal contributors

12 *Corresponding author. Email address: denlinger.1@osu.edu

\section{Abstract}

The extreme seasonal shifts of daylength in polar regions, ranging from constant light in the summer to constant darkness in the winter, pose an intriguing environment for probing activity

17 rhythms and the functioning of circadian clocks. Here, we monitor locomotor activity during the summer on the Antarctic Peninsula and under laboratory conditions, as well as the accompanying

19 patterns of clock gene expression in the Antarctic midge, the only insect endemic to Antarctica.

20 Larvae and adults are most active during the warmest portion of the day, but at a constant 
21 temperature they remain continuously active regardless of the photoregime, and activity also

22 persists in constant darkness. The canonical clock genes period, timeless, Clock, and vrille are

23 expressed in the head but we detected no cycling of expression in either the field or under

24 diverse photoregimes in the laboratory. The timekeeping function of the clock has possibly been

25 lost, enabling the midge to opportunistically exploit the unpredictable availability of permissive

26 thermal conditions for growth, development, and reproduction during the short summer in

27 Antarctica.

Keywords: polar biology, circadian rhythms, clock genes, natural conditions, continuous light

31 Abbreviations: Bmall, Brain and muscle ARNT-like 1; Clk, Clock; cry, cryptochrome; FDR,

32 false discovery rate; LED, light emitting diode; LD, light-dark; PCR, polymerase chain reaction; 33 per, period; qPCR, quantitative PCR; rp 49, ribosomal protein 49; tim, timeless; vri, vrille; ZT, 34 Zeitgeber time.

\section{Introduction}

37

In spite of our rapidly expanding knowledge of biological clocks in diverse species from

39 tropical and temperate latitudes (Sandrelli et al., 2008; Young and Kay, 2009), it is not at all

40 clear how time-keeping mechanisms function in polar environments where the seasonal change

41 in day length is most dramatic, ranging in the extreme from constant light in summer to constant

42 darkness in winter. Of particular interest is how the circadian clock functions during the polar 
43 summer with protracted periods of light (Bloch et al., 2013), a condition that leads to

44 arrythmicity in species from lower latitudes.

Activity and hormonal rhythms persist during the summer in some polar animals: bumble bees in the high Arctic continue to display rhythms of foraging (Stelzer and Chittka, 2010), a

47 rhythm of melatonin release is observed in the willow warbler (Silverin et al., 2009) and in the

48 Lapland longspur (Ashley et al., 2013), and a daily rhythm of body temperature is noted in

49 Arctic ground squirrels during the summer (Williams et al., 2012), but in Antarctic penguins,

50 rhythms of melatonin, prolactin (Miché et al., 1991; Cockrem, 1991) and corticosterone (Vleck

51 and van Hook, 2002) appear to stop. Among four Arctic-breeding birds, substantial variation in

52 daily activity rhythms are noted, depending on species, sex and breeding stage (Steiger et al.,

53 2013). Interestingly, Norwegian reindeer (van Oort et al., 2005) and the Svalbard ptarmigan

54 (Reierth and Stokkan, 1998) show rhythmic behavior in the spring and fall, but switch to

55 arrhythmic behavior in the summer. Less is known about the functioning of the clock mechanism

56 in polar environments. Cultured fibroblasts from reindeer display little or no rhythmicity in

57 expression of the clock genes Bmall and per2 (Lu et al., 2010), while a daily rhythm of cry2 is

58 evident in Antarctic krill (Teschke et al., 2011). Where rhythms have been documented there is

59 little evidence to suggest whether the cycles are in direct response to daily environmental

60 perturbations or represent a functional circadian clock.

In this study we seek evidence for an activity rhythm in the Antarctic midge, Belgica antarctica (Diptera), and monitor expression of the major clock genes that would be expected to

63 drive such a rhythm. This midge is the southernmost free-living insect and is the only insect

64 endemic to Antarctica, where it has a patchy distribution along the western coast of the Peninsula,

65 between $61-68^{\circ} \mathrm{S}$ (Convey and Block, 1996). Two years are required for completion of larval 
development; larvae pupate, emerge as wingless, non-feeding adults in early January, mate, lay eggs and die within 7-10 days after adult eclosion. At this latitude the summer sun briefly drops below the horizon at night, but civil twilight persists; light intensity remains above that of full moonlight (0.2-0.5 lx), the threshold used by temperate insects to distinguish day from night (Beck, 1980). And, during cloudy days, light intensity can sometimes drop below that of the night. Thus, light is available, albeit in varying intensity, throughout the $24-\mathrm{h}$ day. Air temperature during the summer on the Antarctic Peninsula at Palmer Station is usually slightly above freezing but varies, especially in response to sunlight intensity. Adult midges are present in the field only during the extremely long day lengths around the time of the summer solstice; larvae experience the annual range of extreme photoperiods but are active only as long as the substrate remains unfrozen (late-December to mid-March) and are encased in ice most of the year.

\section{Materials and Methods}

\subsection{Collection and maintenance of insects}

Larvae and adults of B. antarctica Jacobs were collected in the vicinity of Palmer Station, Antarctica (64 46’ S, 64 04' W) during January-March 2011 and 2012, but adults were available only during the first two weeks of January in both field seasons. Substrate containing larvae was shipped to Ohio State University in temperature controlled containers (ca. $4^{\circ} \mathrm{C}$ for one week) and subsequently larvae were maintained at $4^{\circ} \mathrm{C}$ and a LD 18:6 photoperiod, with high humidity. Larvae could be maintained under such conditions for more than 12 months, but we were not able to propagate the midges in the laboratory. 
2.2 Activity monitoring

92

Activity was monitored in January 2012 (Table 1). Larvae (4-5 mm) and adults (2-3 mm) were placed individually in wells (22 $\mathrm{mm}$ diameter) of a 12-well tissue culture plate on the day of collection. Moist filter paper was placed at the bottom of each well to prevent desiccation, and no food was provided. Adults do not feed at all, and larvae readily survive more than a week without food, indicating that lack of food is unlikely to be an unnatural condition. Activity levels did not change for most individuals throughout the recording period. Movements of larvae and adults appeared to be natural and did not appear to be restricted by the size of the arena. Some larvae followed the edge of the well, but many others moved throughout the central portion of the well. Adults moved freely throughout the arena.

Although activity monitoring was initiated for more adults, 3-4 day records were obtained for only 5 males. We do not suspect that death of adults was caused by handling, unnatural conditions or sickness, but rather was the consequence of the adult's short life span: males live 8 days on average, and females die within a day after oviposition, resulting in a generally shorter life span of 5 days (Harada et al., 2014). The field-collected adults were of unknown age at the time of collection, and a further 2-day period of laboratory acclimation restricted the number of adults that could be monitored for multiple days with the limited number of cameras available during the narrow time window when adults were present.

Depending on the experiment, plates were placed either outdoors near the station at a site protected from direct sunlight or in an environmental room at ca. $4^{\circ} \mathrm{C}$. Digital images were captured using a webcam equipped with an infrared LED (DC-NCR13U or DC-NCR20U, Hanwha Japan, Tokyo; $\lambda \max =870 \mathrm{~nm}$ ) every $2 \mathrm{~s}$ for adults or every $20 \mathrm{~s}$ for larvae, using 
114 camera-controlling software (LiveCapture2; http://www2.wisnet.ne.jp/ daddy/). Images were

115 manually reviewed and rhythmicity was determined by the Lomb-Scargle test in ActogramJ

116 (Schmidt et al., 2011). The start of the 24-h day in field experiments was designated as sunrise

117 (see Table 1) or by time of lights-on in laboratory conditions. An infrared LED was used for

118 experiments conducted under photoperiodic conditions in the environmental room. The LED was

119 not needed under outdoor conditions because light intensity in the field was sufficient for

120 recording, even after sunset.

121 Table 1.

122 Environmental conditions prevailing at Palmer Station, Antarctica on the dates we observed locomotory

123 activity in field samples of the midge Belgica antarctica during the summer of 2012

\begin{tabular}{lcccccccc}
\hline $\begin{array}{l}\text { Locomotor } \\
\text { activity }\end{array}$ & \multirow{2}{*}{ Date } & LD & Sunrise & Sunset & $\begin{array}{c}\text { Civil } \\
\text { Dawn }\end{array}$ & $\begin{array}{c}\text { Civil } \\
\text { Dusk }\end{array}$ & $\begin{array}{c}\text { Tmax } \\
\left({ }^{\circ} \mathrm{C}\right)\end{array}$ & $\begin{array}{c}\text { Tmin } \\
\left({ }^{\circ} \mathrm{C}\right)\end{array}$ \\
\hline Adults & Jan 8-12th & $21: 3$ & $3: 02-3: 16$ & $23: 41-23: 30$ & no & no & 15.2 & -1.2 \\
Larvae & Jan 13-18th & $20: 4$ & $3: 20-3: 39$ & $23: 27-23: 11$ & no & no & 18.3 & -0.8 \\
\hline
\end{tabular}

124

125 Times of sunrise / sunset and civil dawn / dusk were obtained from the online database of the United

126 States Naval Observatory. Civil twilight is defined by a $6^{\circ}$ angle of the sun below the horizon, reflecting

127 illumination of approximately 1 lux. At this latitude the center of the sun did not drop below $6^{\circ}$ of the

128 horizon between Nov 18 and Jan 24 . Tmax, Tmin $\left({ }^{\circ} \mathrm{C}\right)$ refer to maximum and minimum air temperatures

129 recorded by HOBO loggers during the experimental periods.

\subsection{RNA extraction and $q P C R$}

134 Petri dish and maintained under field conditions; 20 adults or larvae were decapitated every $4 \mathrm{~h}$ 
135 for $24 \mathrm{~h}$ (first time point was sunrise; see Table 2) and heads were transferred to RNA Later ICE 136 (Ambion).

137 Table 2.

138 Environmental conditions prevailing at Palmer Station, Antarctica on the dates we monitored clock gene 139 expression in field samples of the midge Belgica antarctica during the summer of 2012

\begin{tabular}{llccccccc}
\hline $\begin{array}{l}\text { Expression } \\
\text { profiles }\end{array}$ & Date & LD & Sunrise & Sunset & $\begin{array}{c}\text { Civil } \\
\text { Dawn }\end{array}$ & $\begin{array}{c}\text { Civil } \\
\text { Dusk }\end{array}$ & $\begin{array}{c}\text { Tmax } \\
\left({ }^{\circ} \mathrm{C}\right)\end{array}$ & $\begin{array}{c}\text { Tmin } \\
\left({ }^{\circ} \mathrm{C}\right)\end{array}$ \\
\hline Adults & Jan 9th & $21: 3$ & $3: 05$ & $23: 38$ & no & no & 5.6 & -0.4 \\
Larvae & Jan 10th & $21: 3$ & $3: 09$ & $23: 36$ & no & no & 5.5 & 0.4 \\
& Jan 25th & $19: 5$ & $4: 11$ & 22.44 & $0: 48$ & $2: 10$ & 4.3 & 0 \\
\hline
\end{tabular}

140

141 Times of sunrise / sunset and civil dawn / dusk were obtained from the online database of the United

142 States Naval Observatory. Civil twilight is defined by a $6^{\circ}$ angle of the sun below the horizon, reflecting

143 illumination of approximately 1 lux. At this latitude the center of the sun did not drop below $6^{\circ}$ of the

144 horizon between Nov 18 and Jan 24 . Tmax, Tmin $\left({ }^{\circ} \mathrm{C}\right)$ refer to maximum and minimum air temperatures

145 recorded by HOBO loggers during the experimental periods.

For laboratory entrainment, larvae were entrained two weeks under light or temperature

148 regimes and then rapidly frozen at $-80^{\circ} \mathrm{C}$ at $4 \mathrm{~h}$ intervals (Zeitgeber time $\mathrm{ZT} 0=$ lights-on), using 14920 heads/sample. RNA was isolated using a RiboPure Kit (Ambion) and cDNA was synthesized 150 from $1 \mu \mathrm{g}$ total RNA using SuperScript VILO Mix (Invitrogen). 5x diluted cDNA was used as a 151 template for qPCR (iQ SYBR Green Supermix, Bio-Rad). qPCR conditions were as follows:

152 initial denaturation at $94^{\circ} \mathrm{C}$ for $2 \mathrm{~min}$, followed by $20 \mathrm{sec}$ at $94^{\circ} \mathrm{C}, 10 \mathrm{sec}$ at $60^{\circ} \mathrm{C}(\mathrm{rp} 49$, per, tim) 153 or $65^{\circ} \mathrm{C}(\mathrm{Clk}, v \mathrm{ri}), 20 \mathrm{sec}$ at $72^{\circ} \mathrm{C}, 35-40$ cycles. We also cloned partial genomic sequences of the 154 four circadian clock genes (per, tim, Clk, vri) and the reference gene $r p 49$. Genomic DNA was 155 isolated from 1-2 larval bodies using DNeasy Blood \& Tissue Kit (Qiagen). Intron-overlapping 
156 primers for per, tim, Clk and rp49 are listed in Table 3, and their positions are shown in

157 Supplementary data 3.

158 Table 3.

159 Gene-specific primers used in qPCR.

\begin{tabular}{|c|c|c|c|}
\hline Transcript & Primer & Primer sequence $5 `-3$ & $\begin{array}{l}\text { Product size } \\
\text { (bp) }\end{array}$ \\
\hline \multirow[t]{2}{*}{ period } & forward & GTATGCACTCAAACACTCACATCAG^CCTG & 126 \\
\hline & reverse & CTGCTGCTGGCGGACGATTCGAG & \\
\hline \multirow[t]{2}{*}{ timeless } & forward & CGACTGAAGGCGTCTCCATCAA^TGGC & 170 \\
\hline & reverse & CAGTTGCTGGACGACAGCGATTCTGG & \\
\hline \multirow[t]{2}{*}{ Clock } & forward & AAAACAGTTCACTTAGTCAG^CGGTC & 161 \\
\hline & reverse & GTGAGGCATGAAGTTCGTTGACTG & \\
\hline \multirow[t]{2}{*}{ vrille } & forward & CGACCAATCCACTCGAAAACTTCG & 151 \\
\hline & reverse & ATGTTCTTGATGGTGTGGATTTCCG & \\
\hline \multirow[t]{2}{*}{$r p 49$} & forward & CGGACCGATATGACAAAGTCAAG^GAAGC & 149 \\
\hline & reverse & GAAGCCGTTGGGGAGCATGTGGC & \\
\hline
\end{tabular}

160

Intron position is marked with a caret $\left(^{\wedge}\right)$.

162

Background-subtracted fluorescence data was exported from Bio-Rad iQ5 software.

164 Relative Log Concentration (RLC) was computed similar to Larionov (Larionov et al., 2005),

165 utilizing standard curves that were performed for each primer set. A crossing threshold of 0.2

166 was used throughout. Parameters estimated from multiple standard curves from the same primer

167 set were averaged. The RLC for technical replicates were averaged. Normalized RLCs (NRLC)

168 were computed by subtracting the RLC of the control gene, $r p 49$, from the RLC of the gene of

169 interest. Normalized mRNA levels were computed by $10^{\wedge}($ NRLC). Normalized mRNA levels

170 were centered about 1 by dividing the average of normalized mRNA level for each combination

171 of gene of interest and environmental exposure, producing relative mRNA levels 
An analysis of variance (ANOVA) with all pair wise comparisons was performed in

177 SigmaPlot on the relative mRNA levels for each combination of gene of interest and

178 environmental exposure. The family wise error rate was controlled via the Holm-Sidak method

179 for each combination that passed the F-test. Because of the potential of increased sensitivity, 180 circadian activity was modeled for each combination using nlinfit in MATLAB. The circadian

181 model $\{\mathrm{y}=\mathrm{p} 1+\mathrm{p} 2 * \cos (2 * \mathrm{pi} *(\mathrm{ZT}-\mathrm{p} 3) / 24)\}$ was fit to relative mRNA levels and a model

182 utility test was performed against the reduced model $\{\mathrm{y}=\mathrm{p} 1\}(\mathrm{F}(2, \mathrm{~N}-3))$. Additionally a

183 randomization test (100,000 simulations) was performed on $\mathrm{R}^{2}$. False Discovery Rate (FDR) was 184 controlled according to Benjamini and Hochberg (1995).

\section{Results and Discussion}

187

Activity patterns of larvae and adult males were monitored for 5 and 4 days, respectively, under field conditions during the polar summer. All larvae showed significant rhythmicity in

192 locomotor activity, with a periodicity of $23.9 \pm 0.4 \mathrm{~h}$, mean $\pm \mathrm{SD}$ (Fig. 1A). All but one adult 193 displayed a rhythmic activity pattern with a period $24.5 \pm 1.1 \mathrm{~h}$ (Fig. 1B). Under these natural 
194 conditions both larvae and adults displayed rhythmic patterns, with peak activity coinciding with 195 the highest daily temperatures and light intensities.

1973.2 Absence of activity rhythms under photoperiodic conditions at constant temperature

To test whether activity patterns observed in the field were driven by the daily light cycle, larval activity was also monitored in newly-field collected larvae at a constant temperature of 4.9

$201 \pm 0.3^{\circ} \mathrm{C}$ (near the prevailing mean January air temperature at Palmer Station) under a daily

202 photoregime of $21 \mathrm{~h}$ light and $3 \mathrm{~h}$ dark (LD 21:3, a regime that corresponds to the natural light

203 regime the larvae received in the field in January) for 2 days, and then after transfer to constant

204 darkness (Fig. 1C). Four of 10 larvae showed significant rhythmicity at LD 21:3, however 205 rhythmicity persisted in only one larva in constant darkness (larva no. 4 in Supplementary data 206 1). Following transfer to constant darkness, 3 of 10 larvae maintained high activity throughout, 207 while the other 6 showed diverse patterns with discontinuous bursts of activity. When compared 208 with the conspicuously rhythmic activity observed under field conditions, profound activity 209 peaks were abolished under laboratory conditions when two light-dark cycles were followed by 210 two days of constant darkness. We cannot discount the possibility that additional days of 211 recording may have revealed low amplitude rhythms that we did not detect under our 212 experimental regime.

213 Adults, pretrained in the field during a time when daylength (sunrise to sunset) was 214 approximately $21 \mathrm{~h}$, were transferred to the laboratory and subjected to one LD 21:3 cycle, 215 followed by two days of constant darkness and constant temperature (Fig. 1D). Adults displayed 216 behavioral patterns that differed from those observed in the field. Unlike the observations with 
217 field adults, there was no peak of activity during the photophase, and no significant rhythmicity

218 was observed under constant darkness, except for one specimen with a long and rather obscure

219 period (adult no. 5 in Supplementary data 1). Unlike the field adults, adults were more active

220 during the scotophase under laboratory conditions when temperature was held constant. This

221 suggests that locomotor activity in the field is predominantly temperature dependent, as

222 temperature drops at night and activity ceases as well. Under laboratory conditions with a

223 continuously favorable constant temperature, the scotophase may be a slightly preferred time for

224 activity.

225 Monitoring activity patterns in adults of $B$. antarctica is especially challenging due to

226 their short life span, their limited availability restricted to a 1-2 week window in early January,

227 and the inability to generate adults in culture. Thus, meeting the standards of chronobiology

228 research done on Drosophila is not realistic, yet we argue that the results we have obtained

229 strongly support our research interpretation. To the best of our knowledge these actograms are

230 the first recorded for a polar insect in its natural habitat.

$231 \quad$ Larvae exposed to constant light and a thermocycle with a $19 \mathrm{~h}$ thermophase of $4.5^{\circ} \mathrm{C}$ and

$2325 \mathrm{~h}$ cryophase of $-1.9^{\circ} \mathrm{C}$, followed by constant $2.5^{\circ} \mathrm{C}$ were active during the $4.5^{\circ} \mathrm{C}$ thermophase

233 and at a constant temperature of $2.5^{\circ} \mathrm{C}$, but ceased moving immediately when temperature

234 dropped to $-1.9^{\circ} \mathrm{C}$ (Fig. 1E). What is clear from this set of experiments is that larvae quickly

235 responded to changes in temperature, and at the cryophase temperature employed here, activity

236 stopped and then quickly restarted when the larvae were again exposed to a higher temperature. 
Full length sequences of the circadian clock genes period and timeless and partial

241 sequences of Clock and vrille were obtained. Sequences suggest no conspicuous features

242 predicting anything unusual about these genes. No deletions or insertions that would appear to

243 interfere with translation are present in the sequences.

244 Baper encodes a 1083 amino acid (aa) protein; the genomic sequence contains 9 introns

245 within the coding sequence and one long intron $(1.6 \mathrm{~kb})$ at the 5'UTR; the aa sequence has

246 39.9\% identity with DmPER (aligned by Clustal W, DNASTAR Inc.). The relatively low

247 similarity is consistent with the fact that per is a rapidly evolving gene showing high variability

248 outside the PAS domains. Identity is $63 \%$ within the PAS domains of these two species,

249 including $80 \%$ and $57 \%$ for PAS-A and PAS-B, respectively. The nuclear localization signal

250 (RKKKK) is present at the 5'end of the gene. Like many other species, Baper lacks the TG-

251 repeats present in D. melanogaster.

252 Batim encodes a 1148 aa protein, and the genomic sequence contains 9 introns.

253 Alignment of BaTIM and DmTIM shows 47.2\% overall aa identity with $61.3 \%$ and $58.3 \%$

254 identity in PER1 and PER2 domains, respectively.

The partial genomic sequence of $B a C l k$ contains 5 introns and encodes a 515 aa protein

256 that includes a PAS domain. Alignments of BaCLK and DmCLK show $46 \%$ overall identity and

$25760.6 \%$ identity of their PAS domains. The Bavri sequence encodes a 588 aa protein, lacks

258 introns, and shows $32 \%$ overall aa identity to DmVRI and $90.6 \%$ aa identity within the bZIP

259 domains. 
260 Protein alignments of the clock genes of Drosophila melanogaster and B. antarctica are

261 presented in Supplementary data 3. Sequences were deposited in GenBank: KF437828,

262 KF437829, KF437830, KF437831.

Within larval heads, expression of per, tim and Clk was restricted to the brain, whereas

$264 v r i$ was also expressed in non-brain tissues (Supplementary data 2, Fig. 2A).

265

3.4 No cycling of clock genes in field populations during the Antarctic summer

267

Daily expression profiles of clock genes were monitored in both larvae and adults to

269 determine whether they show the cyclic patterns of expression well documented in temperate

270 species. Expression profiles of the circadian clock genes were determined in heads of larvae (Fig.

271 2A) and adults (Fig. 2B) collected under field conditions. The circadian clock genes per, vri and

$272 C l k$ do not cycle under field conditions (modeled by nlinfit in MATLAB, FDR > 0.05; tested by

273 ANOVA, per $\mathrm{df}=9, F=1.24, P=0.31 ;$ vri $\mathrm{df}=9, F=0.68, P=0.73 ; C l k \mathrm{df}=9, F=1.3, P=$

274 0.28). The ANOVA analysis shows a significant differential expression for timeless $(\mathrm{df}=9$,

$275 F=2.47, P=0.04)$, however there is no evidence for cycling (MATLAB, $F D R>0.05$ ). The

276 results presented for the adults must be considered preliminary due to the limited number of

277 adults available for sampling, yet the data are consistent in supporting noncyclical expression of

278 clock genes in the field.

279 
As a next step, we assessed expression of clock genes in the laboratory at constant

temperatures and photoperiods, including constant light at $10^{\circ} \mathrm{C}, \mathrm{LD} 21: 3$ at $5^{\circ} \mathrm{C}$, and LD 12:12 at $10^{\circ} \mathrm{C}$ (Figure $2 \mathrm{C}$ ). With constant light at $10^{\circ} \mathrm{C}$, none of the four clock genes showed rhythmicity (MATLAB, $F D R>0.05$ ) or differential expression (ANOVA, tim $\mathrm{df}=6, F=0.32$, $P=0.91 ;$ per $\mathrm{df}=6, F=0.38, P=0.88 ;$ vri $\mathrm{df}=6, F=0.64, P=0.69 ; C l k \mathrm{df}=6, F=1.19, P=$ 0.37). At long day length (LD 21:3) and $5^{\circ} \mathrm{C}$, only vri displayed evidence for cycling when fitted to a circadian model $(F D R<0.05)$, but the data showed no significant temporal pattern by ANOVA $(\mathrm{df}=7, F=2.40, P=0.07)$. Under LD 12:12 and $10^{\circ} \mathrm{C}$, per, vri, and $C l k$ did not cycle (MATLAB, $F D R>0.05 ;$ ANOVA, per $\mathrm{df}=6, F=0.49, P=0.8 ; C l k \mathrm{df}=6, F=1.01, P=0.43$; vri $\mathrm{df}=6, F=1.98, P=0.1$ ); tim showed significant temporal patterns (ANOVA, tim $\mathrm{df}=7, F=$ $6.81, P<0.001)$ supporting oscillation $(F D R<0.05)$, but phase and amplitude do not correspond to tim expression patterns noted in Drosophila melanogaster (Sehgal et al., 1995) or other insect species (Gentile et al., 2009; Codd et al., 2007; Kobelkova et al., 2010).

To validate our methodology we also monitored tim expression in heads of $D$. melanogaster (Supplementary data 2, Fig. 2B) and showed that the amplitude of change in tim from B. antarctica (Batim) is far lower (1.8 fold change) than we observed at the same photoperiod for the tim transcript from D. melanogaster (Dmtim) (22 fold change), and the phases of maximum and minimum expression differ (max. ZT8, min. ZT24 for Batim; max. ZT16, min. ZT4 for Dmtim). Although slight oscillations were noted for Batim in LD 12:12 and Bavri in LD 21:3, oscillations were of extremely low amplitude, peaked at the "wrong" time, were not consistent among different photoregimes tested, and did not oscillate in concert with expected partner clock genes. In the field, larvae of Belgica would experience LD 12:12 in midMarch and mid-September, at which times they are frozen solid within an encasement of ice, 
thus the LD 12:12 experiments were not ecologically relevant but provided a photoregime that could easily be compared to data from temperate species.

The lack of cyclic transcription of clock genes in the heads of adults and larvae under field and laboratory conditions offers several hypotheses about the circadian clock mechanism in this species. Cycling of per and tim also does not occur in D. melanogaster and other insect species under constant light or under extremely long days, with photophases longer than $16 \mathrm{~h}$ (Qiu et al., 1996, Codd et al., 2007; Kobelkova et al., 2015). But, lack of per, vri and Clk rhythmic expression and only mild and atypical tim cycling in the midge under experimental conditions of LD 12:12 suggests that these clock genes fail to cycle under a range of photophases, not only extremely long photophases. Our observations suggest that the Antarctic midge lost the capacity for rhythmic expression of the clock genes. We recognize, of course, that a photoregime of LD 12:12 is not ecologically relevant for this species because adults are not present during that time of year, and larvae are already frozen solid in an ice matrix.

In addition to long photophases, low temperature is another factor known to be capable of halting clock function. Fruit flies are completely inactive in winter when temperatures are lower than $10^{\circ} \mathrm{C}$; at such temperatures, PER and TIM are not detectable (Menegazzi et al., 2013). Low temperature is clearly a limiting factor for activity, reproduction and survival of Drosophila, a species that is of tropical origin. But, the situation of the Antarctic midge is quite different. The temperatures we used for our experiments were low by temperate zone standards but were within the normal temperature range for this species. This midge is most active and reproduces during the polar summer, with prevailing air temperatures between $-2^{\circ} \mathrm{C}$ and $+10^{\circ} \mathrm{C}$. It is thus unlikely that the temperatures used in these experiments would be interpreted as being sufficiently cold to compromise rhythmic transcription in the midge. 
Although we argue strongly that the transcription of the clock genes is not cyclic in the 329 Antarctic midge, we cannot discount the possibility that the clock proteins cycle in the absence of RNA cycling, as reported for certain situations in D. melanogaster (Yang and Sehgal, 2001).

331 Clock protein cycling in the absence of transcript cycling is an intriguing possibility worthy of 332 future attention. Attempts to measure levels of PER and TIM in the midge brain using antibodies 333 from Drosophila thus far have failed (data not shown), thus we anticipate that it will be 334 necessary to generate antibodies specific to $B$. antarctica to adequately address this question.

It is quite possible that the circadian clock mechanism in $B$. antarctica is completely turned-off. Clearly, the clock genes are still present and transcribed in B. antarctica, but in

337 addition to their well-defined role as mediators of circadian events, clock genes are involved in 338 regulating diverse non-clock activities, including oogenesis (Beaver et al., 2003), long-term 339 memory formation (Sakai et al., 2004), development (George and Terracol, 1997) and gut 340 function (Bajgar et al, 2013). Within the brain of D. melanogaster, clock genes are expressed in

341 both neural and non-neural cells, and only a subset of neurons carry out circadian clock functions

342 (Kaneko and Hall, 2000; Kaneko et al., 1997; Ewer et al., 1992). Thus, the clock genes are 343 indispensible, displaying a wide array of functions, and expression persists even in the absence 344 of a clock function.

\section{Conclusions}

We have shown that rhythmic behavior observed under natural condition during the polar 349 summer does not correlate with cyclic expression of the canonical clock genes. In a similar 350 fashion, certain Drosophila clock mutants also show high levels of rhythmicity under natural 
351 (Vanin et al., 2012) and pseudo-natural conditions (Menegazzi et al., 2012), suggesting that 352 temperature affects the fly activity pattern more strongly than photoperiod under natural 353 conditions (Menegazzi et al., 2013). Our observations with the Antarctic midge are consistent

354 with the idea that the activity cycles observed in the field are primarily a direct response to 355 changes in prevailing temperatures rather than the light-dark cycle.

356 Warmth is at a premium in the challenging polar environment, and we suspect that our 357 observations reflect an adaptation by the midge to maximize and fully exploit permissive, but 358 unpredictable, thermal conditions for feeding, development and reproduction during the brief 359 austral summer. As long as temperatures are sufficiently high, the midge remains active, 360 disregarding daily light-dark cycles that are so pervasive in dictating activity rhythms in 361 temperate and tropical animals. And, correlated with an activity pattern that is directly 362 responsive to thermal conditions, the midge lacks the rhythmic pattern of clock gene expression 363 that drives many activity rhythms at lower latitudes.

365 Acknowledgements

366 We thank Palmer Station staff for support provided during our field seasons and Martina 367 Hajduskova for assistance in preparing figures of the activity patterns. This work was supported 368 by National Science Foundation OPP-ANT-0837613 and OPP-ANT-0837559.

\section{References}


371 Ashley, N.T., Schwabl, I, Goymann, W, Buck, C.L., 2013. Keeping time under the midnight sun:

372 Behavioral and plasma melatonin profiles of free-living Lapland longspurs (Calcarius lapponicus) during the arctic summer. J. Exp. Zool. 319A, 10-22. (doi: 10.1002/jez.1768)

374

375

376

377

378

379

380

381

382

383

384

385

386

387

388

389

390

391

392

Bajgar, A., Jindra, M., Dolezel, D., 2013. Autonomous regulation of the insect gut by circadian genes acting downstream of juvenile hormone signaling. Proc. Natl. Acad. Sci. USA 110, 4416-4421. . (doi: 10.1073/pnas.1217060110)

Beaver, L.M., Rush, B.L., Gvakharia, B.O., Giebultowicz, J.M., 2003. Noncircadian regulation and function of clock genes period and timeless in oogenesis of Drosophila melanogaster. J. Biol. Rhythms 18, 463-472. (doi: 10.1177/0748730403259108)

Beck, S. D., 1980. Insect Photoperiodism. New York: Academic Press.

Benjamini, Y., Hochberg, Y., 1995. Controling the false discovery rate: A practical and powerful approach to multiple testing. J R Statist Soc B 57: 289-300. (doi: 10.2307/2346101)

Bloch, G., Barnes, B.M., Gerkema, M.P., Helm, B., 2013. Animal activity around the clock with no overt circadian rhythms: Patterns, mechanisms, and adaptive value. Proc. R. Soc. B 280, 20130019. (doi: 10.1098/rspb.2013.0019)

Cockrem, J.F., 1991. Plasma melatonin in the Adelie penguin (Pygoscelis adeliae) under continuous daylight in Antarctica. J. Pineal. Res. 10, 2-8. (doi: 10.1111/j.1600079X.1991.tb00457.x)

Codd, V., Dolezel, D., Stehlik, J., Piccin, A., Garner, K.J., Racey, S.N., Straatman, K.R., Louis, E.J., Costa, R., Sauman, I., Kyriacou, C.P., Rosato, E., 2007. Circadian rhythm gene regulation in the housefly Musca domestica. Genetics 177, 1539-1551. (doi:

10.1534/genetics.107.079160) 
393 Convey, P., Block, W., 1996. Antarctic Diptera: Ecology, physiology and distribution. Eur. J. 394 Entomol. 93, 1-13.

395 Ewer, J., Frisch, B., Hamblen-Coyle, M.J., Rosbash, M., Hall, J.C., 1992. Expression of the 396 period clock gene within different cell types in the brain of Drosophila adults and mosaic 397 analysis of these cells' influence on circadian behavioral rhythms. J. Neurosci. 12, 3321$398 \quad 3349$.

399

400

401

402

403

404

405

406

407

408

409

410

411

412

413

Gentile, C., Rivas, G.B.S., Meireles-Filho, A.C.A., Lima, J.B.P., Peixoto, A.A., 2009. Circadian expression of clock genes in two mosquito disease vectors: cry2 is different. J. Biol. Rhythms 24, 444-451. (doi: 10.1177/0748730409349169)

George, H., Terracol, R., 1997. The vrille gene of Drosophila is a maternal enhancer of decapentaplegic and encodes a new member of the bZIP family of transcription factors. Genetics 146, 1345-1363.

Harada, E., Lee, R.E., Denlinger, D.L., Goto, S.G., 2014. Life history traits of adults and embryos of the Antarctic midge Belgica antarctica. Polar Biol. 37, 1213-1217. (doi: 10.1007/s00300-014-1511-0)

Kaneko, M., Helfrich-Förster, C., Hall, J.C., 1997. Spatial and temporal expression of the period and timeless genes in the developing nervous system of Drosophila: Newly identified pacemaker candidates and novel features of clock gene product cycling. J. Neurosci. 17, $6745-6760$.

Kaneko, M., Hall, J.C., 2000. Neuroanatomy of cells expressing clock genes in Drosophila: Transgenic manipulation of the period and timeless genes to mark the perikarya of circadian 
pacemaker neurons and their projections. J. Comp. Neurol. 422, 66-94. (doi:

$$
\text { 10.1002/(SICI)1096-9861(20000619)422:1<66::AID-CNE5>3.0.CO;2-2) }
$$

Kobelkova, A., Bajgar, A., Dolezel, D., 2010. Functional molecular analysis of a circadian clock gene timeless promoter from the drosophilid fly Chymomyza costata. J. Biol. Rhythms 25, 399-409. (doi: 10.1177/0748730410385283)

Kobelkova, A., Zavodska, R., Sauman, I., Bazalova, O., Dolezel, D., 2015. Expression of clock genes period and timeless in the central nervous system of the Mediterranean flour moth, Ephestia kuehniella. J. Biol. Rhythms 30,104-16. (doi: 10.1177/0748730414568430)

Larionov, A., Krause, A., Miller, W., 2005. A standard curve based method for relative real time PCR data processing. BMC Bioinformatics 6: 62. (doi:10.1186/1471-2105-6-62)

Lu, W., Meng, Q-J., Tyler, N.J.C., Stokkan, K-A., Loudon, A.S.I., 2010. A circadian clock is not required in an arctic mammal. Curr. Biol. 20, 533-537. (doi: 10.1016/j.cub.2010.01.042)

Menegazzi, P., Yoshii, T. \& Helfrich-Förster, C., 2012. Laboratory versus nature: The two sides of the Drosophila circadian clock. J. Biol. Rhythms 27, 433-442. (doi:

$$
10.1177 / 0748730412463181)
$$

Menegazzi, P., Vanin, S., Yoshii, T., Rieger, D., Hermann, C., Dusik, V., Kyriacou, C. P., Helfrich-Förster, C., Costa, R., 2013. Drosophila clock neurons under natural conditions. J. Biol. Rhythms 28, 3-14. (doi: 10.1177/0748730412471303)

Miché, F., Vivien-Roels, B., Pévet, P., Spehner, C., Robin, J.P., Le Maho, Y., 1991. Daily pattern of melatonin secretion in an antarctic bird, the emperor penguin, Aptenodytes forsteri: Seasonal variations, effect of constant illumination and of administration of isoproterenol or propranolol. Gen. Comp. Endocrinol. 84, 249-263. (doi: 10.1016/0016-6480(91)90048-B) 
Qiu, J., Hardin, P.E., 1996. per mRNA cycling is locked to lights-off under photoperiodic conditions that support circadian feedback loop function. Mol. Cell Biol. 16, 4182-4188.

Reierth, E., Stokkan, K-A., 1998. Activity rhythm in High Arctic Svalbard ptarmigan (Lagopus mutus hyperboreus). Can. J. Zool. 76, 2031-2039. (doi: 10.1139/cjz-76-11-2031)

Sakai, T., Tamura, T., Kitamoto, T., Kidokoro,Y., 2004. A clock gene, period, plays a key role in long-term memory formation in Drosophila. Proc. Natl. Acad. Sci. USA 101, 16058-16063. (doi: 10.1073/pnas.0401472101)

Sandrelli. F., Costa, R., Kyriacou, C.P., Rosato, E., 2008. Comparative analysis of circadian clock genes in insects. Insect Mol. Biol. 17, 447-463. (doi: 10.1111/j.13652583.2008.00832.x)

Schmid, B., Helfrich-Förster, C., Yoshii, T., 2011. A new ImageJ plugin "ActogramJ" for chronobiological analyses. J. Biol. Rhythms 26, 464-467. (doi: 10.1177/0748730411414264)

Sehgal, A., Rothenfluh-Hilfiker, A., Hunter-Ensor, M., Chen, Y., Myers, M.P., Young, M.W., 1995. Rhythmic expression of timeless: A basis for promoting circadian cycles in period gene autoregulation. Science 270, 808-810. (doi:10.1126/science.270.5237.808)

Silverin, B., Gwinner, E., Van't Hof, T.J., Schwabl, I., Fusani, L., Hau, M., Helm, B., 2009. Persistent diel melatonin rhythmicity during the Arctic summer in free-living willow warblers. Horm. Behav. 56, 163-168. (doi: 10.1016/j.yhbeh.2009.04.002)

Steiger, S. S., Valcu, M., Spoelstra, K., Helm, B., Wikelski, M., Kempenaers, B., 2013. When the sun never sets: Diverse activity rhythms under continuous daylight in free-living arcticbreeding birds. Proc. R. Soc. B 280, 20131016. (doi: 10.1098/rspb.2013.1016) 
457 Stelzer, R.J., Chittka, L., 2010. Bumblebee foraging rhythms under the midnight sun measured 458 with radiofrequency identification. BMC Biol. 8, 93. (doi:10.1186/1741-7007-8-93)

459 Teschke, M., Wendt, S., Kawaguchi, S., Kramer, A., Meyer, B., 2011. A circadian clock in 460 Antarctic krill: An endogenous timing system governs metabolic output rhythms in the $461 \quad$ euphausid species Euphausia superba. PLoS ONE 6, e26090. (doi:

462 463 van Oort, B. E. H., Tyler, N. J. C, Gerkema, M. P., Folkow, L., Blix, A. S., Stokkan, K-A., 2005. 464 Circadian organization in reindeer. Nature 438, 1095-1096. (doi: 10.1038/4381095a)

465 Vanin, S., Bhutani, S., Montelli, S., Menegazzi, P., Green, E. W., Pegoraro, M., Sandrelli, F., 466 Costa, R., Kyriacou, C. P., 2012. Unexpected features of Drosophila circadian behavioural 467 rhythms under natural conditions. Nature 484, 371-375. (doi: 10.1038/nature 10991)

468 Vleck, C.M., van Hook, J. A., 2002. Absence of daily rhythms of prolactin and corticosterone in 469 Adelie penguins under continuous daylight. The Condo 104, 667-671. (doi: 10.1650/0010470 5422(2002)104[0667:AODROP]2.0.CO;2)

471 Williams, C.T., Barnes, B.M., Richter, M., Buck, C.L., 2012. Hibernation and circadian rhythms 472 of body temperature in free-living arctic ground squirrels. Physiol. Biochem. Zool. 85, 397473 404. (doi: 10.1086/666509)

474 Yang, Z., Sehgal, A., 2001. Role of molecular oscillations in generating behavioral rhythms in 475 Drosophila. Neuron 29, 453-467. (doi: 10.1016/S0896-6273(01)00218-5)

476 Young, M.W., Kay, S.A., 2009. Time zones: A comparative genetics of circadian clocks. Nat. $477 \quad$ Rev. Genet. 2, 702-715. (doi:10.1038/35088576) 
Figure legends

480

481

482

483

484

485

486

487

488

489

490

491

492

493

494

495

496

497

498

499

500

Fig. 1. Locomotory activity of Belgica antarctica under field and laboratory conditions. Field monitoring of larvae (A) and adults (B) occurred during the austral summer in Antarctica. Laboratory experiments on larvae (C) and adults (D) monitored activity at $4.9 \pm 0.3^{\circ} \mathrm{C}$ with a photoperiod of LD 21:3, followed by constant darkness. Larval activity (E) was determined using a thermoperiod of $4.5^{\circ} \mathrm{C}$ for $19 \mathrm{~h}$ and $\left(-1.9^{\circ} \mathrm{C}\right)$ for $5 \mathrm{~h}$, followed by $2.5^{\circ} \mathrm{C}$ in constant light. Mean activity is plotted in blue (+ SD, gray) together with light intensity (log lx; yellow) and temperature $\left({ }^{\circ} \mathrm{C}\right.$; red). Number of individuals $(\mathrm{n})$ is indicated in each diagram. Individual actograms presented in Supplementary data 1, Fig. 1A-E.

Fig. 2. Daily expression profiles of circadian clock genes in larval and adult heads of Belgica antarctica from the field or in the laboratory under different photoregimes. Transcript levels of period, timeless, vrille and Clock were measured by quantitative PCR. (A) Larvae used for the field data were collected under the natural conditions that prevailed at two different dates in January, during the austral summer at Palmer Station, Antarctica (Jan. 10, solid line and open rectangle; Jan. 25, broken line and open triangle). Each time point represents an independent biological repeat. Light intensity (log lux, yellow) and temperature $\left({ }^{\circ} \mathrm{C}\right.$, red) were measured during the corresponding days; sunrise and sunset are designated with arrows (A; lower panels). (B) Adults were collected under the natural conditions on Jan, 9 (solid line and open diamonds) during the austral summer at Palmer Station, Antarctica. Each time point represents an independent biological repeat. Light intensity (log lux, yellow) and temperature $\left({ }^{\circ} \mathrm{C}\right.$, red) were measured during the corresponding day; sunrise and sunset are designated with arrows (B; lower panel). (C) Three different photoperiods were used to entrain larvae in the laboratory 
501 experiments: LD 12:12 (solid line), LD 21:3 (broken line), LL (dotted line). Open and black bars 502 below graphs refer to light (L) and dark (D) periods. Significant oscillations for tim and vri 503 mRNAs (both $F D R<0.05$ ) are highlighted in red. Each time point represents an average of 504 independent biological repeats: $\mathrm{n}=5$ for LD 12:12; $\mathrm{n}=3$ for LD 21:3 and LL. Error bars 505 indicate $\pm \mathrm{SD}$. 
FigureV

Figure 1
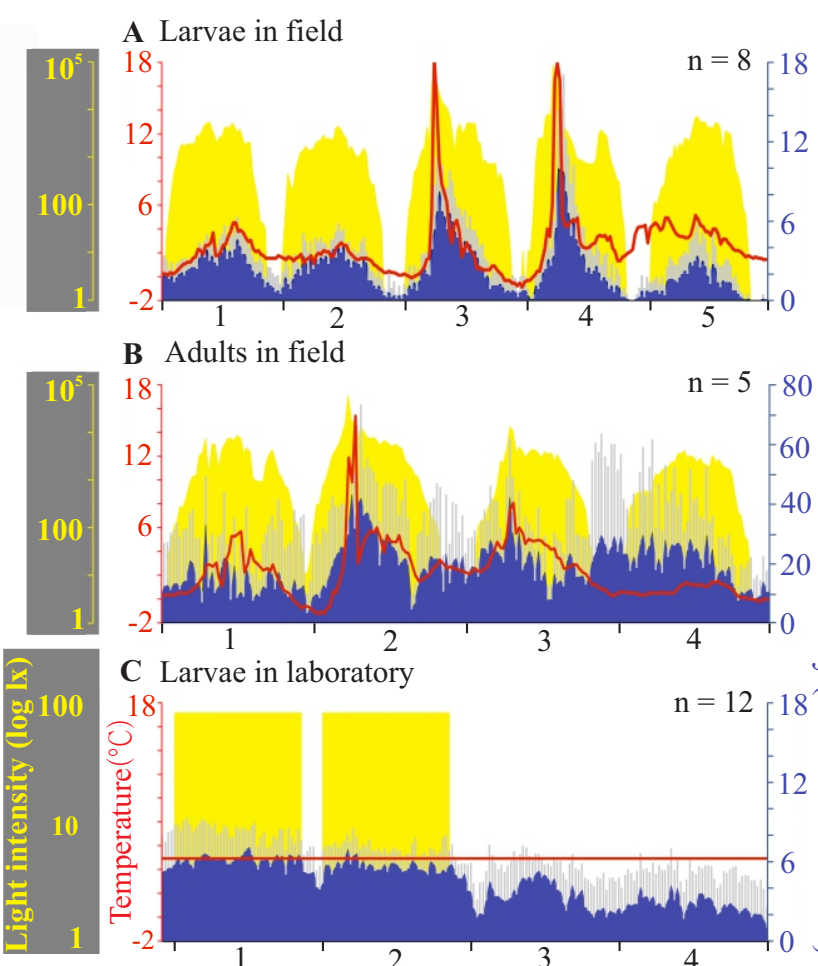
B Adults in field

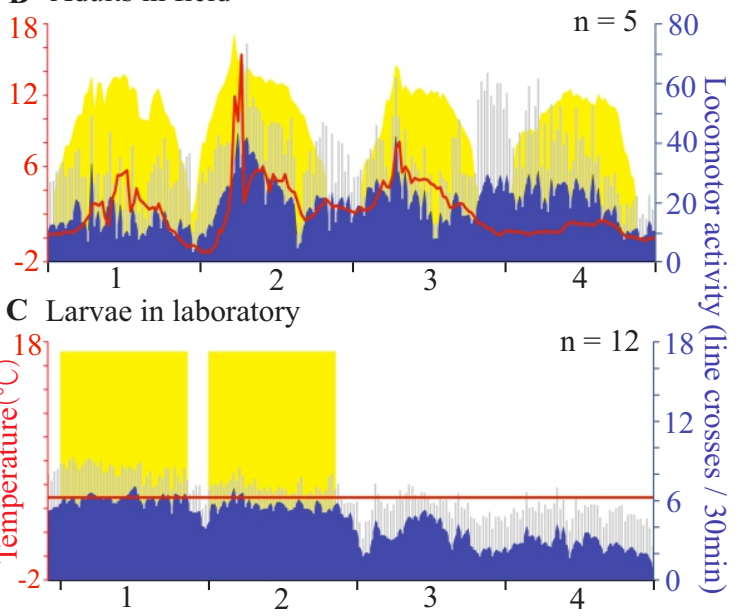

D Adults in laboratory

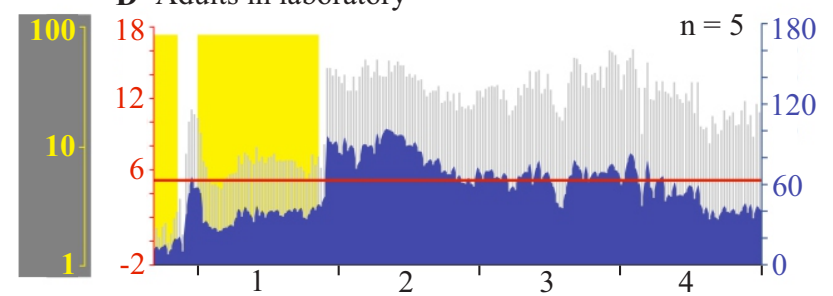

E Larvae in laboratory
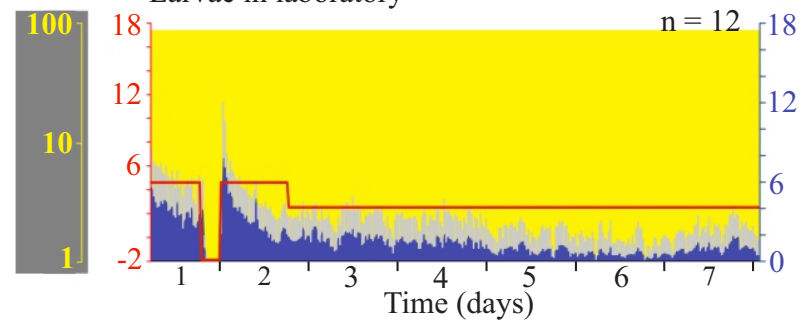
Figure 2

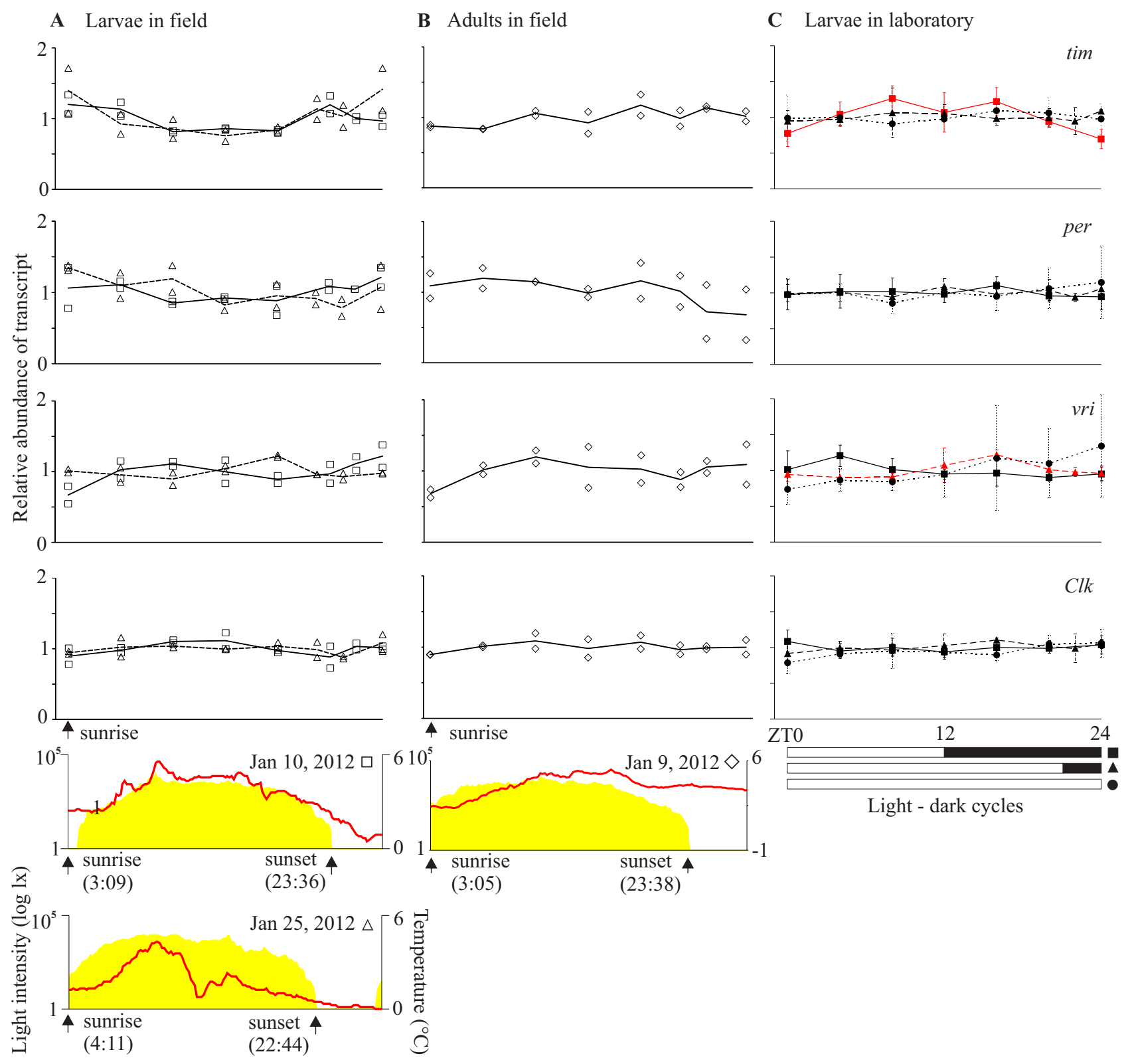


Graphical Abstract

\section{Polar summer with extremely long days}

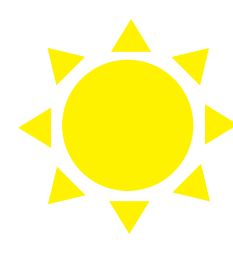

Antarctic midge

the only insect endemic to Antarctica

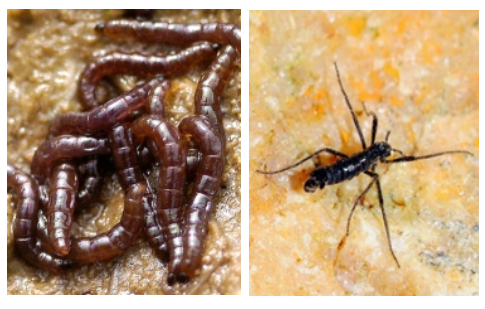

\section{Biological rhythms}

Temperature dependent locomotor activity

No cycling of circadian clock genes 